\title{
D-cycloserine does not facilitate fear extinction by reducing conditioned stimulus processing or promoting conditioned inhibition to contextual cues
}

\author{
Kathryn D. Baker, ${ }^{1}$ Gavan P. McNally, and Rick Richardson \\ School of Psychology, The University of New South Wales, Sydney 2052, Australia
}

\begin{abstract}
The NMDA receptor partial agonist D-cycloserine (DCS) enhances the extinction of learned fear in rats and exposure therapy in humans with anxiety disorders. Despite these benefits, little is known about the mechanisms by which DCS promotes the loss of fear. The present study examined whether DCS augments extinction retention (1) through reductions in conditioned stimulus (CS) processing or (2) by promoting the development of conditioned inhibition to contextual cues. Rats administered DCS prior to extinction showed enhanced long-term extinction retention (Experiments 3 and 4). The same nonreinforced CS procedure used in extinction also reduced freezing at test when presented as pre-exposure before conditioning, demonstrating latent inhibition (Experiment 1). DCS administered shortly prior to pre-exposure had no effect on latent inhibition using parameters which produced weak (Experiment 2) or strong (Experiment 3) expression of latent inhibition. Therefore, DCS facilitated learning involving CS-alone exposures, but only when these exposures occurred after (extinction) and not before (latent inhibition) conditioning. We also used a retardation test procedure to examine whether the extinction context gained inhibitory properties for rats given DCS prior to extinction. With three different footshock intensities, there was no evidence that DCS promoted accrual of associative inhibition to the extinction context (Experiment 4). The present findings demonstrate that DCS does not facilitate extinction by reducing CS processing or causing the extinction context to become a conditioned inhibitor. Investigations into the mechanisms underlying the augmentation of extinction by DCS are valuable for understanding how fear can be inhibited.
\end{abstract}

The extinction of learned fear is widely regarded as a valuable preclinical animal model of exposure-based therapies for human anxiety disorders (Myers and Davis 2002). A common procedure for inducing learned fear involves Pavlovian conditioning where an initially neutral stimulus (the conditioned stimulus [CS]) is paired with an aversive unconditioned stimulus (US). In extinction, repeated presentation of the CS in the absence of the US reduces fear elicited by the CS. Extinction is thought to involve new learning of a CS-no US association and is critically dependent upon $N$-methyl-D-aspartate (NMDA) receptors (Falls et al. 1992; Baker and Azorlosa 1996; Sotres-Bayon et al. 2007, 2009). The decrement in the conditioned response (CR) produced by extinction is not always permanent, because recovery of the CR often occurs when the CS is presented in a different physical context to the extinction context, termed renewal (Bouton and Bolles 1979a). Recovery of the CR may also occur following an unexpected aversive event or re-presentation of the US, referred to as reinstatement (Bouton and Bolles 1979b). Finally, CRs which have been extinguished can spontaneously recover with the passage of time (Quirk 2002; Rescorla 2004).

Despite exposure therapy being an effective treatment for anxiety disorders, the high rate of relapse after treatment is a limitation of such therapies (Hofmann and Smits 2008). Hence, there is considerable interest in developing pharmacological adjuncts that can enhance the loss of fear and reduce relapse phenomena by facilitating learning and memory processes underlying extinction (Graham et al. 2011; Kaplan and Moore 2011). One effective adjunct is D-cycloserine (DCS), an NMDA receptor partial agonist, which facilitates extinction retention in rats (Walker et al. 2002;

\footnotetext{
${ }^{1}$ Corresponding author

E-mail k.baker@unsw.edu.au

Article is online at http://www.learnmem.org/cgi/doi/10.1101/lm.026674.112.
}

Ledgerwood et al. 2003). Importantly, the long-term retention of fear extinction is enhanced by DCS only when within-session extinction occurs (Weber et al. 2007), suggesting that DCS facilitates the learning underlying extinction, rather than reducing levels of state anxiety (see Richardson et al. 2004; Vervliet 2008). DCS reduces some forms of relapse, such as reinstatement, in both rats (Ledgerwood et al. 2004; Bertotto et al. 2006) and humans (Kuriyama et al. 2011) but does not prevent renewal (Woods and Bouton 2006; Bouton et al. 2008). A further benefit is that DCS produces a "generalization of extinction" whereby DCS-treated rats display less fear to a second CS previously paired with the same US but not extinguished (Ledgerwood et al. 2005). DCS has considerable translational value for treatments for human anxiety disorders (Graham et al. 2011; Myers et al. 2011). Specifically, DCS has been shown to have positive therapeutic effects for several anxiety disorders, including social anxiety disorder (Hofmann et al. 2006; Guastella et al. 2008), acrophobia (fear of heights) (Ressler et al. 2004), post-traumatic stress disorder (de Kleine et al. 2012), obsessive-compulsive disorder (Kushner et al. 2007), and panic disorder (Otto et al. 2010; but see Siegmund et al. 2011).

Although there are many theories about the nature of extinction, very little is known about the specific associative mechanisms responsible for enhanced extinction by pharmacological adjuncts like DCS. One account suggests that a reduction in CS processing underlies extinction (Robbins 1990). This explanation proposes that during extinction there is reduced attention (learned inattention) to the nonreinforced CS, which causes decreased conditioned responding. It is possible to test whether DCS facilitates extinction by reducing CS processing using a latent inhibition design. Latent inhibition is the retardation of learning when subjects are given nonreinforced presentations of the stimulus before conditioning (Lubow and Moore 1959; Lubow 1965). 
This reduction in associability has been viewed as a consequence of reduced attention to the pre-exposed CS (Pearce and Hall 1980; Holtzman et al. 2010). Extinction and latent inhibition share many behavioral characteristics, such as being context- and temporally specific (Westbrook et al. 2000; Bouton et al. 2006). In latent inhibition designs, CS-alone exposure occurs before CS-US pairings, whereas for extinction the CS-alone exposure occurs after conditioning. It is well established that DCS promotes learning when the CS is not reinforced during extinction, but it is unknown if DCS may have a similar action on the learning underlying latent inhibition. If DCS alters attention paid to a CS, then it may facilitate learning during CS-alone exposures regardless of whether these occur before (latent inhibition) or after (extinction) conditioning.

A second possibility is that DCS may enhance extinction by promoting the development of conditioned inhibition to the extinction context (Rescorla 1969; Rescorla and Wagner 1972), as suggested by Woods and Bouton (2006) and Vervliet (2008). The Rescorla-Wagner learning rule (Rescorla and Wagner 1972) states that learning is caused by an error signal generated by a difference between the intensity of the actual US and that which was expected. When the CS is presented during extinction, the unexpected absence of the aversive outcome (no US) is surprising. This negative prediction error results in a loss of associative strength to the CS and a reduction in fear. The Rescorla-Wagner model predicts that these changes in associative strength are shared among the target CS and other stimuli concurrently present (Rescorla and Wagner 1972). Therefore, the negative prediction error that drives extinction learning to the target CS can transform other stimuli present during extinction, such as the extinction context, into conditioned inhibitors.

Evidence that the extinction context develops associative inhibition is conflicting, but recent findings suggest that this can occur under certain circumstances (Polack et al. 2012). Importantly, most studies on DCS and fear extinction use a novel context for extinction training and then test animals in that same context (i.e., an ABB design). If DCS enhances extinction learning by augmenting conditioned inhibition to the context, this would explain why DCS prevents reinstatement (Ledgerwood et al. 2004; Bertotto et al. 2006) and the generalization of extinction effect (Ledgerwood et al. 2005) when tested in the extinction context. Reinstatement is thought to involve the re-presented US becoming associated with the extinction context (Bouton 2002). However, if DCS causes the extinction context to become a conditioned inhibitor, the negative associative value of this context should retard the acquisition of a context-US association. When the CS is presented again in the extinction context, the summed associative value of the context and CS will be smaller for animals given DCS and elicit reduced CRs than in saline-treated animals. Therefore, DCS-treated animals would be resistant to reinstatement of fear to the CS. Similarly, the generalization of extinction effect can be accounted for by the negative associative value of the extinction context negating the positive associative value of a nonextinguished CS, causing reduced CRs in DCS-treated animals. Thus, there should be no effect on responding to the CS outside of the extinction context. Consistent with this possibility, DCS does not prevent ABA renewal (Woods and Bouton 2006). The two cardinal tests for conditioned inhibition are summation and retardation tests (Rescorla 1969). A stimulus must pass both tests to be deemed a conditioned inhibitor. The evidence reviewed above shows that for DCS-treated rats, the extinction context passes the summation test for both the extinguished CS and an independently trained excitor (Ledgerwood et al. 2004, 2005). Thus, the experiments reported here studied whether the extinction context passes a retardation test. A retardation test assesses learning of an excitatory association between a CS (or context) and a US
(Rescorla 1969). If DCS promotes the development of conditioned inhibition to the extinction context, then subsequent fear conditioning to that context should be retarded compared to a saline control group.

We directly compared the effects of DCS on fear extinction and latent inhibition to examine whether DCS promotes the loss of fear through reductions in CS processing. Rats were trained to fear a white-noise CS in one context. Some rats were pre-exposed to the CS before conditioning in a different context. Other rats received extinction in this second context. All rats were tested for fear to the CS in the pre-exposure/extinction context. Prior to either pre-exposure or extinction, rats received systemic injections of DCS or saline. We next investigated whether DCS causes the extinction context to become inhibitory using a retardation test. One day after an extinction retention test, rats received an unsignalled footshock in the extinction context. Fear learning to that context was assessed the following day by measuring levels of freezing when rats were returned to the extinction context.

\section{Results}

\section{Experiment 1: CS pre-exposures that produce weak or strong latent inhibition}

DCS facilitates extinction retention when extinction parameters (e.g., six CS presentations, 2 min each with a 2-min inter-trial interval [ITI]) produce within-session extinction but poor extinction retention in control rats (Ledgerwood et al. 2003). Experiment 1 examined whether the same six CS-alone procedures would be effective at reducing test performance when presented prior to conditioning (i.e., did this procedure cause latent inhibition?). The design is shown in Table 1 . In this experiment, rats in three groups received either zero, three, or six CS pre-exposures. All groups were equated on exposure to the context. The next day, rats were conditioned to the CS in a different context (two CS-US pairings) and then tested the following day for fear to the CS (two CS-alone presentations) in the same context as pre-exposure.

There were low levels of freezing to CS presentations during pre-exposure ( $<6 \%$ per trial). No freezing $(0 \%)$ to the CS was observed in any animal on the first conditioning trial. During the second conditioning trial, mean CS-elicited freezing for the no pre-exposure group increased to $31.25 \% \quad(\mathrm{SEM}=12.74)$. The groups that had received three or six CS pre-exposures showed a minimal increase in freezing during conditioning (three CS: Mean $=6.25 \%$, SEM $=6.25$; six CS: Mean $=1.25 \%$, SEM $=1.25$ ). Analyses of these data showed that freezing significantly increased across conditioning trials $\left(F_{(1,21)}=7.40, P=0.013\right)$. A significant pre-exposure $\times$ trial interaction confirmed that the pre-exposed groups showed a significantly slower rate of acquisition than the no pre-exposure group $\left(F_{(1,21)}=7.45, P=0.013\right)$, with no significant group differences in the rate of acquisition between the three and six CS pre-exposure groups $(F<1.0, P=0.671)$.

Pre-CS freezing before conditioning, extinction, and test was low (Mean $<12 \%$, SEM $<6 \%$ ) for all experiments. There were no significant group differences in pre-CS freezing in any experiment. Test performance is shown in Figure 1. There was a significant effect of trial $\left(F_{(1,21)}=5.57, P=0.028\right)$, indicating overall performance decreased on trial 2. Groups pre-exposed to the CS showed significantly lower freezing at test compared to the no preexposure group $\left(F_{(1,21)}=15.72, P=0.001\right)$, confirming the presence of latent inhibition. Rats receiving six CS pre-exposures froze significantly less at test (i.e., more latent inhibition) than those receiving three CS pre-exposures $\left(F_{(1,21)}=6.32, P=0.020\right)$. There was no significant interaction of trial with either pre-exposure $\left(F_{(1,21)}=2.93, P=0.102\right)$ or amount of pre-exposure $\left(F_{(1,21)}=\right.$ 1.26, $P=0.275)$. 
Table 1. Experimental designs for Experiments 1-4

\begin{tabular}{|c|c|c|c|c|c|}
\hline Experiment/group & Day 1 & Day 2 & Day 3 & Day 4 & Day 5 \\
\hline Experiment 1 & Pre-exposure (B) & Conditioning (A) & Test (B) & & \\
\hline No pre-exposure & Context & $2 \mathrm{CS}+$ & $2 \mathrm{CS}-$ & - & - \\
\hline 3 CS pre-exposure & $3 \mathrm{CS}-$ & $2 \mathrm{CS}+$ & $2 \mathrm{CS}-$ & - & - \\
\hline 6 CS pre-exposure & $6 \mathrm{CS}-$ & $2 \mathrm{CS}+$ & $2 \mathrm{CS}-$ & - & - \\
\hline Experiment 2 & Pre-exposure (B) & Conditioning (A) & Test (B) & & \\
\hline SAL-3 CS & $\mathrm{SAL} \rightarrow 3 \mathrm{CS}-\rightarrow \mathrm{DCS}$ & $2 \mathrm{CS}+$ & $2 \mathrm{CS}-$ & - & - \\
\hline DCS-3 CS & $\mathrm{DCS} \rightarrow 3 \mathrm{CS} \rightarrow \rightarrow \mathrm{SAL}$ & $2 \mathrm{CS}+$ & $2 \mathrm{CS}-$ & - & - \\
\hline SAL-6 CS & $\mathrm{SAL} \rightarrow 6 \mathrm{CS}-\rightarrow \mathrm{DCS}$ & $2 \mathrm{CS}+$ & $2 \mathrm{CS}-$ & - & - \\
\hline Experiment 3 & Pre-exposure (B) & Conditioning $(\mathrm{A})$ & Extinction (B) & Test (B) & \\
\hline SAL-Ext & - & $2 \mathrm{CS}+$ & $\mathrm{SAL} \rightarrow 6 \mathrm{CS}-\rightarrow \mathrm{DCS}$ & $2 \mathrm{CS}-$ & - \\
\hline DCS-Ext & - & $2 \mathrm{CS}+$ & $\mathrm{DCS} \rightarrow 6 \mathrm{CS}-\rightarrow \mathrm{SAL}$ & $2 \mathrm{CS}-$ & - \\
\hline SAL-LI & $\mathrm{SAL} \rightarrow 6 \mathrm{CS}-\rightarrow \mathrm{DCS}$ & $2 \mathrm{CS}+$ & - & $2 \mathrm{CS}-$ & - \\
\hline DCS-LI & $\mathrm{DCS} \rightarrow 6 \mathrm{CS}-\rightarrow \mathrm{SAL}$ & $2 \mathrm{CS}+$ & - & $2 \mathrm{CS}-$ & - \\
\hline Experiment 4 & Conditioning (A) & Extinction (B) & Test (B) & Context Conditioning (B) & Retardation Test (B) \\
\hline SAL-0.4 mA & $2 \mathrm{CS}+$ & $\mathrm{SAL} \rightarrow 6 \mathrm{CS}-\rightarrow \mathrm{DCS}$ & $2 \mathrm{CS}^{-}$ & 0.4-mA shock & Context \\
\hline DCS- $0.4 \mathrm{~mA}$ & $2 \mathrm{CS}+$ & $\mathrm{DCS} \rightarrow 6 \mathrm{CS}-\rightarrow \mathrm{SAL}$ & $2 \mathrm{CS}-$ & 0.4-mA shock & Context \\
\hline SAL- $0.8 \mathrm{~mA}$ & $2 \mathrm{CS}+$ & $\mathrm{SAL} \rightarrow 6 \mathrm{CS}-\rightarrow \mathrm{DCS}$ & $2 \mathrm{CS}-$ & $0.8-\mathrm{mA}$ shock & Context \\
\hline DCS- $0.8 \mathrm{~mA}$ & $2 \mathrm{CS}+$ & $\mathrm{DCS} \rightarrow 6 \mathrm{CS} \rightarrow \rightarrow \mathrm{SAL}$ & $2 \mathrm{CS}-$ & $0.8-\mathrm{mA}$ shock & Context \\
\hline SAL-1.0 mA & $2 \mathrm{CS}+$ & $\mathrm{SAL} \rightarrow 6 \mathrm{CS}-\rightarrow \mathrm{DCS}$ & $2 \mathrm{CS}-$ & 1.0-mA shock & Context \\
\hline DCS-1.0 mA & $2 \mathrm{CS}+$ & $\mathrm{DCS} \rightarrow 6 \mathrm{CS}-\rightarrow \mathrm{SAL}$ & $2 \mathrm{CS}-$ & 1.0-mA shock & Context \\
\hline
\end{tabular}

The experimental context is designated by letters in parentheses. $(+)$ A 0.6-mA footshock US. Injections occurred 15 min prior to and $4 \mathrm{~h}$ after pre-exposure or extinction.

\section{Experiment 2: DCS administered prior to CS pre-exposure has no effect on the development of latent inhibition}

The previous experiment demonstrated that rats receiving three or six CS pre-exposures showed less freezing at test compared to rats which were not pre-exposed to the CS, confirming the presence of latent inhibition. Further, rats receiving six CS preexposures exhibited a stronger latent inhibition effect than those given three CS pre-exposures. Experiment 2 examined whether DCS administered prior to CS pre-exposures affected the learning underlying latent inhibition. Rats received a subcutaneous injection of DCS or saline 15 min before the CS pre-exposure session. There were three groups in this experiment: Saline-3CS, DCS$3 \mathrm{CS}$, and Saline-6CS. Further details of the design are shown in Table 1. DCS was administered prior to three CS pre-exposures because this amount produced an intermediate level of fear and, therefore, would allow detection of either increased or decreased levels of freezing at test.

During pre-exposure trials, CS-elicited freezing was minimal $(\leq 2 \%)$ across each group. All rats showed no freezing (0\%) during the first conditioning trial. Statistical analyses revealed that overall, freezing increased significantly during the second conditioning trial (Saline-6CS: Mean $=0 \%$; Saline-3CS: Mean $=9.09 \%$, $\mathrm{SEM}=4.15 ;$ DCS-3CS: Mean $=10.91 \%, \quad \operatorname{SEM}=6.67 ; \quad F_{(1,29)}=$ $6.07, P=0.020)$. The rate of acquisition did not differ between the groups (pre-exposure $\times$ trial interaction $F_{(1,29)}=1.85, P=$ 0.182; drug $\times$ trial interaction $F<1.0$ ).

CS-elicited freezing at test is shown in Figure 2. Overall, there was more freezing on the first trial. This was confirmed by a significant main effect of trial $\left(F_{(1,29)}=10.15, P=0.003\right)$. In the saline groups, there was a significant main effect of pre-exposure $\left(F_{(1,29)}=9.24, P=0.005\right)$, replicating the findings of Experiment 1 that six CS pre-exposures resulted in lower overall freezing at test (more latent inhibition) than three CS pre-exposures. Although rats displayed slightly higher levels of freezing at test in Experiment 2 than rats in Experiment 1, this may be due to the animals receiving injections before the pre-exposure phase in Experiment 2 but not in Experiment 1. There was no significant interaction of trial with either pre-exposure amount or drug $(F s<$ 1.0). Comparing the groups receiving three CS pre-exposures, DCS and saline-treated rats showed similar levels of overall freezing at test $(F<1.0)$, demonstrating that DCS had no effect on the development of latent inhibition using parameters that produced weak latent inhibition.

\section{Experiment 3: DCS facilitates learning during CS-alone exposures in extinction but not latent inhibition}

The results of Experiment 2 suggest that DCS administered prior to CS pre-exposure has no effect on the expression of latent inhibition. Experiment 3 aimed to extend these findings by comparing the effects of DCS on extinction and latent inhibition in the same experiment. This experiment used a 2 (Extinction, Latent inhibition) $\times 2$ (Saline, DCS) design shown in Table 1 . We used the same six CS-alone presentations in both the CS pre-exposure and extinction conditions. The animals in each of these conditions were injected either with DCS or saline shortly prior to the CS-alone presentations.

There was minimal freezing to the six CS presentations $(<2 \%)$ during pre-exposure for the latent inhibition groups. During the first conditioning trial, none of the groups exhibited any CS-elicited freezing (0\%). CS-elicited freezing during the second conditioning trial was similar across groups (Saline-

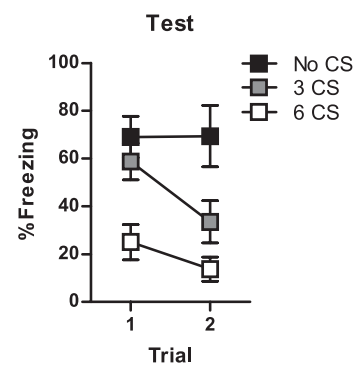

Figure 1. Expression of latent inhibition in rats receiving CS preexposure. Mean ( \pm SEM) freezing to the CS in the pre-exposure context at test in Experiment 1. Rats that received CS pre-exposure prior to conditioning showed less freezing at test (i.e., latent inhibition) than those receiving only context pre-exposure ( $n=8$ for each group). Six CS pre-exposures resulted in less freezing than three CS pre-exposures. 


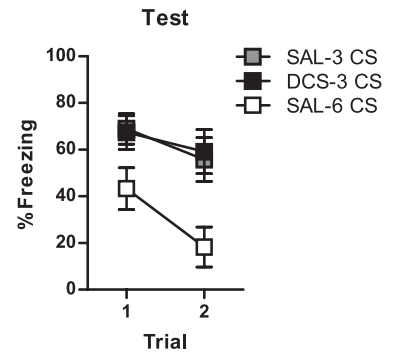

Figure 2. DCS does not affect the development of latent inhibition using parameters that produce weak latent inhibition. Mean ( \pm SEM) CS-elicited freezing in the pre-exposure context at test from Experiment 2. Rats were in one of three groups: Saline-3 CS $(n=11)$, DCS-3 CS $(n=11)$, Saline-6 CS $(n=10)$. Injections of saline (SAL) or DCS occurred 15 min prior to pre-exposure. The DCS-3 CS group showed similar freezing at test compared to the Saline-3 CS group. Six CS pre-exposures produced less freezing than three CS pre-exposures in saline-treated rats.

Extinction: Mean $=8.00 \%$, SEM $=3.59$; DCS-Extinction: Mean $=$ $6.00 \%$, SEM $=2.67$; Saline-Latent inhibition: Mean $=7.00 \%$, $\mathrm{SEM}=4.96$; DCS-Latent inhibition: Mean $=14.00 \%, \quad \mathrm{SEM}=$ 5.62). Statistical analyses revealed that overall freezing was significantly higher during the second conditioning trial $\left(F_{(1,36)}=\right.$ 16.10, $P<0.001)$. There was no significant interaction of trial with either condition or drug $(F s<1)$ and no significant condition $\times$ drug $\times$ trial interaction $\left(F_{(1,36)}=1.06, P=0.310\right)$, confirming that the rate of acquisition did not differ between groups. Although rats in the extinction groups showed somewhat lower levels of freezing during the second conditioning trial than might be expected (and compared to similar groups in Experiments 1 and 4), there was clear evidence of learning because these rats showed high levels of CS-elicited freezing during the first extinction trial (see Fig. 3A). Statistical analyses revealed that levels of freezing significantly decreased across extinction trials $\left(F_{(1,18)}=97.14, P<0.001\right)$. There was no significant drug effect $\left(F_{(1,18)}=1.32, P=0.266\right)$, or drug $\times$ trial interaction $(F<1.0)$, indicating that rats in the saline and DCS extinction groups showed a similar rate of extinction and overall levels of fear.

Test performance is displayed in Figure 3B. Test data were analyzed using a condition by drug by trial mixed-design ANOVA. Freezing significantly decreased on test trial 2 across groups $\left(F_{(1,36)}=4.33, P=0.045\right)$. There were no overall significant differences in levels of freezing between extinction and latent inhibition groups $\left(F_{(1,36)}=3.89, P=0.056\right)$ or saline and DCS groups $\left(F_{(1,36)}=2.39, P=0.131\right)$. Importantly, a significant drug $\times$ condition interaction was revealed $\left(F_{(1,36)}=4.33, P=0.045\right)$, indicating that the difference in freezing between groups receiving saline and DCS was greater for the extinction condition than for the latent inhibition condition. No other interactions were significant (largest $\left.F_{(1,36)}=1.27, P=.267\right)$. Further analyses confirmed that rats receiving DCS prior to extinction had significantly lower levels of freezing at test than did the animals given saline prior to extinction $\left(F_{(1,36)}=6.58, P=0.015\right)$. In contrast, the rats given DCS prior to CS pre-exposure exhibited similar levels of CS-elicited freezing at test as did those animals given saline prior to being preexposed to the CS $(F<1)$. This shows that when using identical nonreinforced CS presentations, DCS facilitates long-term extinction retention but has no effect on the development of latent inhibition.

\section{Experiment 4: DCS does not promote the development of conditioned inhibition to contextual cues}

Experiment 4 used the retardation procedure to assess whether DCS causes the extinction context to become a conditioned in- hibitor. The primary question in this experiment was whether rats given DCS at the time of extinction would subsequently show impaired conditioning to that context compared to rats receiving saline. All rats were conditioned in one context followed by extinction and test in a second context. Shortly before extinction, rats were injected with DCS or saline. One day after the extinction retention test, rats received an unsignalled footshock in the extinction context. Three different US intensities were used $(0.4,0.8$, and $1.0 \mathrm{~mA})$. The following day, rats were returned to the extinction context, and contextual freezing was measured. This experiment used a 2 (Saline, DCS $) \times 3(0.4,0.8$, and $1.0 \mathrm{~mA})$ design as summarized in Table 1.

At training, CS-elicited freezing was very low for all rats on the first trial $(<1 \%)$ but increased on the second trial (Saline: Mean $=25.39 \%, \quad$ SEM $=4.65 ; \quad$ DCS: Mean $=29.64 \%, \quad$ SEM $=$ 5.81). Statistical analyses revealed that there was significantly more overall freezing during the second CS presentation $\left(F_{(1,52)}=53.14, P<0.001\right)$. A nonsignificant effect of drug $(F<$ $1)$ and a nonsignificant drug $\times$ trial interaction $(F<1)$ confirmed that overall levels of freezing and the rate of acquisition did not differ between the saline and DCS groups.

There was evidence of within-session extinction in both the saline and DCS groups (Fig. 4A). Freezing significantly decreased across trials $\left(F_{(1,52)}=335.02, P<0.001\right)$. There was no significant effect of drug $(F<1)$ or interaction of drug and extinction trial $(F<1)$, confirming that saline and DCS-treated rats showed a similar rate of extinction and overall levels of fear. When tested the following day (see Fig. 4B), drug free, those animals previously given DCS exhibited significantly lower levels of freezing than did saline-treated rats $\left(F_{(1,52)}=4.75, P=0.034\right)$, demonstrating that DCS facilitated extinction retention. Freezing decreased significantly on the second test trial across both drug groups $\left(F_{(1,52)}=\right.$ 34.91, $P<0.001)$, but there was no interaction between drug and test trial $(F<1)$, suggesting that DCS reduced fear across both trials.

One day after the extinction retention test, rats received an unsignalled footshock $(0.4,0.8$, or $1.0 \mathrm{~mA})$ in the extinction context. Figure 5 presents levels of contextual freezing in the extinction context the following day. The level of freezing was related to the intensity of the shock (i.e., more freezing in rats given the higher intensity shock). At each intensity of the shock, rats given DCS or saline exhibited similar levels of freezing. A mixed-model ANOVA with the factors of US intensity, drug, and test minute confirmed these observations. Levels of freezing significantly increased and decreased over the 5-min retardation test (quadratic
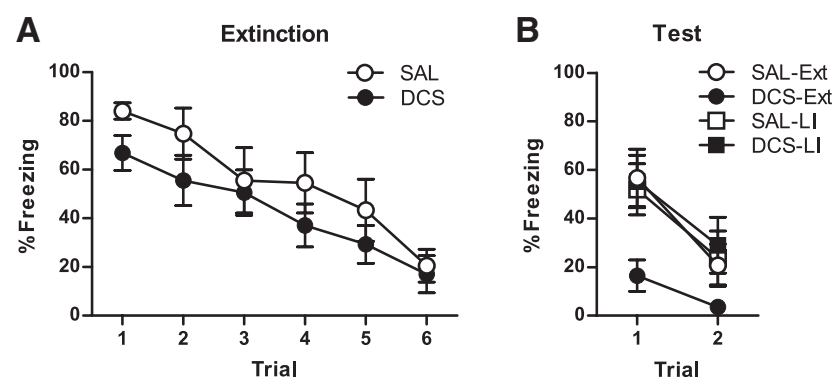

Figure 3. DCS facilitates extinction retention but has no effect on latent inhibition. Mean ( \pm SEM) freezing to the CS across extinction $(A)$ and test $(B)$ from Experiment 3. Rats in the latent inhibition (LI) groups received six CS-alone presentations before conditioning, whereas those in the extinction (Ext) groups received identical CS-alone presentations after conditioning ( $n=10$ for each group). Pre-exposure, extinction, and test were conducted in the same context, but conditioning occurred in a different context. Rats were injected with DCS or saline 15 min prior to preexposure or extinction. 

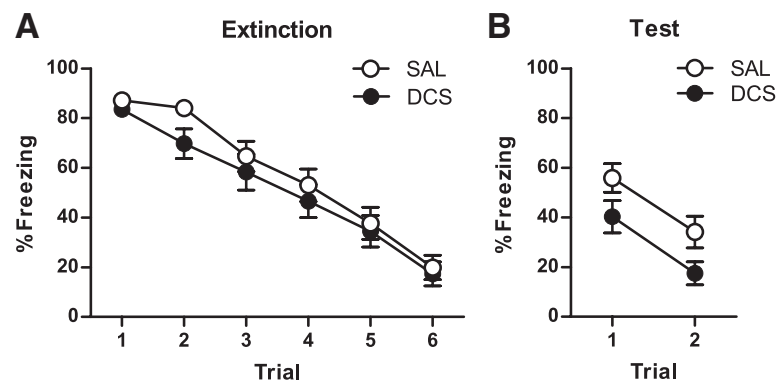

Figure 4. $D C S$ facilitates extinction retention. Mean $( \pm$ SEM) freezing to the CS across extinction $(A)$ and test $(B)$ from Experiment 4. Rats administered DCS $(n=28) 15$ min prior to extinction exhibited less fear at test compared to saline-treated rats $(n=26)$.

trend contrast: $\left.F_{(1,48)}=64.27, P<0.001\right)$. Rats subjected to the higher US intensities exhibited significantly more overall freezing $\left(F_{(1,48)}=6.18, P=0.016\right)$ and a significantly greater increase and decrease in freezing $\left(F_{(1,48)}=7.01, P=0.011\right)$. There was no significant difference between rats receiving the 0.8 or the $1.0 \mathrm{~mA}$ footshock in level of overall freezing $(F<1)$ or across test minutes $\left(F_{(1,48)}=2.78, P=0.102\right)$. Importantly, there were no significant differences in freezing at any US intensity between animals given DCS or saline prior to extinction. There was no significant effect of drug $(F<1)$ and no significant interactions of drug with US intensity or test minute or three-way interaction (largest $F_{(1,48)}=1.13$, $P=0.293$ ). These findings suggest that rats given DCS prior to extinction training in a novel context did not subsequently learn any less about that context and shock than did saline-treated rats. To exclude the possibility that the extinction retention test somehow reduced any inhibitory properties of the extinction context, we conducted a second retardation test with an identical design (using two shock intensities) except without the postextinction test. We replicated the findings of Experiment 4 that animals given DCS did not show any retardation of subsequent conditioning to the extinction context (data not shown). Therefore, there was no evidence, using a retardation test procedure, to support the claim that DCS enhances extinction by causing the extinction context to become a conditioned inhibitor.

\section{Discussion}

The present experiments studied the associative mechanisms underlying how DCS facilitates the extinction of learned fear. These experiments demonstrated that DCS facilitated learning involving CS-alone exposures, but only when these exposures occurred after conditioning (extinction; Experiments 3 and 4). If these CS-alone exposures occurred prior to conditioning, they impaired learning of the CS-US association (i.e., latent inhibition was observed), but DCS did not enhance this learning. More specifically, we first determined procedures that produced either weak or strong latent inhibition (Experiment 1) and then showed that treatment with DCS had no effect on either weak (three CS pre-exposures; Experiment 2) or strong (six CS pre-exposures; Experiment 3) latent inhibition. Other experiments examined whether treatment with DCS at the time of extinction training transforms the extinction context into a conditioned inhibitor; this was assessed by measuring subsequent fear learning to that context (i.e., a retardation test). With three different US intensities, there was no evidence that DCS retarded subsequent conditioning to the extinction context (Experiment 4). This was not due to a lack of drug effect because DCS significantly enhanced extinction retention.
Understanding how DCS facilitates extinction is not only theoretically interesting but also practically important. Clinically, DCS has been shown to be an efficacious pharmacological adjunct to exposure-based therapies for anxiety disorders in humans (Ressler et al. 2004; Hofmann et al. 2006; Kushner et al. 2007; Guastella et al. 2008; Otto et al. 2010; de Kleine et al. 2012). The effectiveness of DCS in preventing some forms of relapse (Ledgerwood et al. 2004; Bertotto et al. 2006) and reducing fear to a nonextinguished CS (Ledgerwood et al. 2005) offers considerable benefits for minimizing the recovery of fear after psychological treatment. Although the current results do not explain how DCS facilitates the loss of fear following extinction, they do rule out two theoretical explanations.

Firstly, the findings of the present study suggest that DCS does not augment extinction learning by reducing CS processing through learned inattention to the nonreinforced CS (Robbins 1990). If DCS was promoting learned inattention, treatment with DCS should have enhanced latent inhibition, given that latent inhibition is the cardinal test for such inattention (Pearce and Hall 1980; Holtzman et al. 2010). However, it was demonstrated that DCS enhanced learning about nonreinforced CS
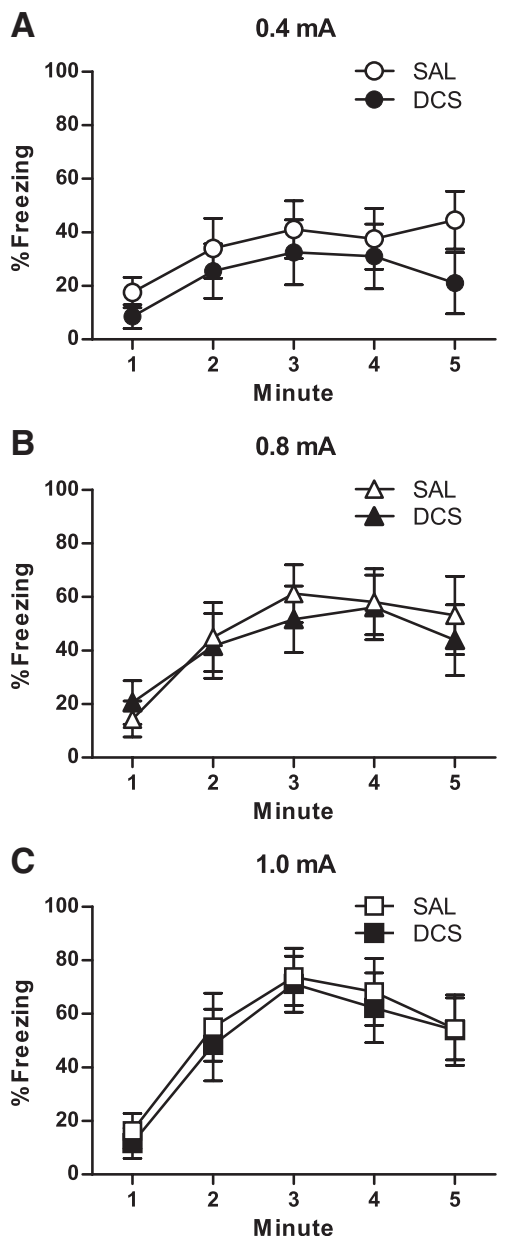

Figure 5. Retardation test performance from Experiment 4. Rats given DCS before extinction did not exhibit any retardation of subsequent conditioning to the extinction context compared to saline-treated rats. Mean ( \pm SEM) freezing to the extinction context following conditioning with a single 0.4- $(A), 0.8-(B)$, or 1.0-mA (C) footshock. Rats were in one of six groups: Saline-0.4 mA $(n=10)$, DCS-0.4 mA $(n=10)$, Saline- $0.8 \mathrm{~mA}$ $(n=8), \mathrm{DCS}-0.8 \mathrm{~mA}(n=9)$, Saline-1.0 mA $(n=8), \mathrm{DCS}-1.0 \mathrm{~mA}(n=9)$. 
presentations when they occur after conditioning (extinction) but not when they occur before (latent inhibition). We administered DCS prior to CS pre-exposure and observed no effect on latent inhibition. Consistent with this finding, the modulation of NMDA receptor function by glycine (administered prior to both preexposure and conditioning) also does not affect latent inhibition (Barak and Weiner 2010). However, DCS given at conditioning may have had a different effect on the expression of latent inhibition. For example, blockade of NMDA receptors during conditioning results in persistent latent inhibition (i.e., latent inhibition is expressed under conditions in which stronger conditioning typically overcomes the effects of CS pre-exposure) (Gaisler-Salomon and Weiner 2003). DCS injected before conditioning effectively disrupts this persistent latent inhibition induced by blockade of NMDA receptors (Gaisler-Salomon et al. 2008). Nonetheless, there was no evidence here to support the possibility that learned inattention to the CS is causal to DCS facilitation of extinction retention.

Secondly, we also demonstrated that the effects of DCS on extinction retention are not a consequence of the extinction context becoming a conditioned inhibitor. When DCS was given at the time of extinction, there was no evidence that these animals subsequently learned any less fear of that context than did saline-treated rats (Experiment 4). In other words, the extinction context did not pass the retardation test (Rescorla 1969). Three intensities of shock were used, and there was a significant effect of shock intensity. Therefore, there was capacity to detect an impairment in context conditioning in the DCS-treated animals. That is, if the extinction context was, indeed, a conditioned inhibitor, then the rats treated with DCS and given a high intensity of shock should have exhibited a comparable level of freezing as those rats given saline and the lower intensity shock. As noted previously, past reports have shown, in effect, that the extinction context passes a summation test for conditioned inhibition. However, a CS must pass both the summation and retardation test to be considered a conditioned inhibitor (Rescorla 1969). Therefore, the findings of the current study suggest that the actions of DCS cannot be attributed to conditioned inhibition to contextual cues.

Having excluded reductions in CS processing and context inhibition, a third possibility is that DCS may reduce the salience of the US representation. It has been suggested that repeated presentations of the CS during extinction activate the representation of the US. In the absence of the actual US, repeated activation of the US representation decreases the affective value of this representation so that it now elicits reduced conditioned responding (Rescorla 1973; Rescorla and Heth 1975). There have not been any direct tests of whether DCS enhances US devaluation, but it is an important possibility because the decrement in fear produced by US habituation, like extinction, is NMDA-dependent (Storsve et al. 2010) and context specific (Storsve et al. 2012). If DCS leads to a general devaluation of the US representation that is not CS-specific, this would explain why DCS given with extinction can reduce fear to another CS previously paired with the US but not extinguished (Ledgerwood et al. 2005), which typically does not occur after extinction (e.g., Richards and Sargent 1983). The observation that DCS prevents reinstatement after extinction (Ledgerwood et al. 2004; Bertotto et al. 2006) can also be explained because a reinstating shock will be less effective in exciting the devalued US representation in DCS-treated animals. However, it is more difficult to interpret the finding that DCS-treated animals show renewal (Woods and Bouton 2006) by predicting that DCS enhances US devaluation. The model proposed by Rescorla and Heth (1975) does not predict renewal of CRs after habituation or extinction because weakening of the US representation should be context-independent. Consistent with this prediction, expression of the unconditioned response (UR) is context-independent after US habituation (Storsve et al. 2012). In contrast, CRs do show renewal after habituation (Storsve et al. 2012), suggesting that expression of the CR in DCS-treated animals may be context-specific, regardless of any augmented US devaluation.

To fully understand how DCS augments extinction, it may be more fruitful to examine the effects of DCS on extinction at the neural level. It has been demonstrated that pre- or postextinction infusions of DCS into the basolateral amygdala (BLA) facilitate extinction retention (Walker et al. 2002; Ledgerwood et al. 2003), suggesting that the amygdala is a possible site of action of DCS during extinction. The consolidation of extinction is also thought to involve NMDA receptors in the infralimbic (IL) region of the medial prefrontal cortex (Sotres-Bayon et al. 2009). DCS is effective in promoting extinction retention under conditions when extinction learning is not effective and may do so through activation of the IL. For instance, compared to adults or juvenile rats which display good extinction retention, adolescent rats show impaired extinction retention and reduced levels of phosphorylated mitogen-activated protein kinase (pMAPK) in the IL after extinction (Kim et al. 2011). Notably, systemic DCS injections overcome this extinction retention deficit in adolescent rats (McCallum et al. 2010). Microinfusions of DCS into the IL in adult rats also enhance the rate of re-extinction under circumstances when extinction fails (i.e., immediate extinction) (Chang and Maren 2011). It would be interesting to determine if infusions of DCS into the IL augment extinction retention under other conditions when extinction retention is impaired, such as in adolescent rats.

Another way that DCS might facilitate the loss of fear is by enhancing the partial erasure or "unlearning" of the fear memory. The observation of relapse phenomena after extinction has typically been interpreted as behavioral evidence against the view that extinction involves erasure of the original fear memory, suggesting instead that extinction actively inhibits fear (Myers and Davis 2002; Quirk and Mueller 2008). However, such recovery or relapse phenomena are typically weak (i.e., do not involve full restoration of the CR) and transient. It has long been noted by associative theorists that the recovery effects are consistent with the erasure of some, but not all, of the original training association (for review, see Delamater 2012). In support of this, neural data have suggested that extinction may reverse some synaptic and structural changes induced by conditioning within the fear circuit (Quirk and Mueller 2008). For example, extinction may reverse conditioning-induced dendritic spine remodeling in prefrontal and frontal regions (Vetere et al. 2011; Lai et al. 2012) and calcineurin-induced dephosphorylation of the transcription factor CREB in the amygdala (Lin et al. 2003). DCS infused into the amygdala before or after extinction reversed conditioning-induced increase in surface expression of GluR1 containing AMPA receptors compared to controls (extinction training alone $24 \mathrm{~h}$ after conditioning, or DCS without extinction) (Mao et al. 2006). These findings raise the exciting possibility that DCS may reverse some conditioning-induced neural changes in the fear circuit. Although erasure of the fear memory trace by DCS cannot be complete if these animals exhibit renewal (Woods and Bouton 2006), even partial erasure of the fear memory by DCS would be valuable for limiting the recovery of fear and relapse after exposure-based therapies. Further research is needed to investigate how DCS alters the fear circuit during extinction.

In conclusion, the mechanisms by which DCS produces a decrement in learned fear remain elusive. The present findings demonstrate that the effects of DCS on extinction are not due to reductions in CS processing or development of conditioned inhibition to contextual cues. Understanding the processes by 
which DCS facilitates extinction, aside from being theoretically important, has relevance for understanding how fear can be inhibited and enhancing therapeutic outcomes of exposure-based therapies.

\section{Materials and Methods}

\section{Subjects}

Subjects were experimentally naive adult male Sprague-Dawley rats obtained from the Animal Resources Centre (Perth, Western Australia). Rats were housed in groups of eight in plastic boxes with food and water available ad libitum. The colony room was maintained on a 12-h light-dark cycle (lights on at $7 \mathrm{am}$ ). Rats were handled for 2-4 min each day for four consecutive days to habituate to the experimenter. All procedures were approved by the Animal Care and Ethics Committee at The University of New South Wales and conducted in accordance with the guidelines of the Australian Code of Practice for the Care and Use of Animals for Scientific Purposes (National Health and Medical Research Council 2004).

\section{Apparatus}

Experiments were conducted in two sets of Med Associates chambers $(24 \mathrm{~cm}$ [length] $\times 30 \mathrm{~cm}$ [width] $\times 21 \mathrm{~cm}$ [height]) to provide two different contexts. Each chamber was enclosed within a sound- and light-attenuating cabinet equipped with a ventilation fan providing constant ventilation and low-level background noise $(\sim 58 \mathrm{~dB})$. Rats were observed using a mounted infrared camera on the rear cabinet wall connected to a DVD recorder and monitor. The chambers were wiped with tap water after each experimental session.

Rats were conditioned in chambers with the ceiling, rear wall, and hinged front door constructed of clear Perspex and stainless steel side walls (referred to as Context A). The floor consisted of stainless steel rods (4-mm diameter, spaced $16 \mathrm{~mm}$ apart center to center) with a stainless steel tray of bedding $3.5 \mathrm{~cm}$ beneath. Two nose poke holes and two key lights were symmetrically located on the right side wall and were inactive during all experiments. Between the nose poke holes, there was a recessed magazine located behind a $5 \times 5-\mathrm{cm}$ opening in the center of the side wall. A speaker was located in the top left corner on the same side wall. Infrared lighting was the only source of illumination in Context A.

The second set of chambers (referred to as Context B) was used for pre-exposure, extinction, test, context conditioning, and retardation tests. Context $\mathrm{B}$ chambers had different visual features, flooring, and lighting than Context A. The ceiling and front wall of the Context B chambers had paper with vertical black and white stripes (2.5-cm width) attached. A clear Perspex insert covered the grid floor, and the stainless steel tray under the floor did not contain any bedding. The Perspex insert was removed for context conditioning sessions (Experiment 4). A white light on top of the chamber provided illumination in Context B.

The CS was a white noise; noise levels increased by $4 \mathrm{~dB}$ above background when the CS was presented. The US was a scrambled 0.6-mA, 1-sec shock delivered through the grid floor. In Experiment 4, a single unsignalled 0.4-, 0.8-, or 1.0-mA, 1-sec footshock was delivered for context conditioning. A computer running Med-PC IV software (Med Associates) controlled all presentations of the CS and US.

\section{Procedure}

\section{CS pre-exposure}

In Experiments 1-3, which examined latent inhibition, some rats were pre-exposed to the CS on Day 1. After a 2-min adaptation period in Context $\mathrm{B}$, three or six white-noise CS presentations, each 2 min long and separated by an ITI of 2 min, were given. Those rats receiving only three CS pre-exposures remained in the chambers an extra 12 min after the last CS presentation. In Experiment 1 , rats in the no CS pre-exposure group were placed in the cham- bers for an equivalent duration (24 min) but received no stimuli. Therefore, all rats were equated on length of context exposure. The parameters for the six CS pre-exposures procedure were identical to those used for extinction in Experiments 3 and 4.

\section{Conditioning}

Fear conditioning occurred in Context A on Day 2 (except for Experiment 4, where it occurred on Day 1). Conditioning was identical in all experiments. After a 2-min adaptation period, the white-noise CS was presented for $10 \mathrm{sec}$ and coterminated with the shock US. A second CS-US pairing was given after a 2-min ITI.

\section{Extinction}

Extinction occurred in Context B (on Day 3 for Experiment 3, Day 2 for Experiment 4 ) and consisted of six nonreinforced presentations of the CS (2 min each; 2-min ITI). These extinction parameters cause a substantial reduction in fear during extinction training but result in a recovery of fear at test in saline-treated animals (Ledgerwood et al. 2003); this recovery permits detection of any facilitatory effect of DCS on extinction retention.

\section{Test}

On Day 3 in Experiments 1, 2, and 4, and Day 4 in Experiment 3, rats were tested for CS-elicited freezing. Two min after being placed in Context B, two CSs were presented for 2 min with an ITI of $2 \mathrm{~min}$.

\section{Retardation procedure}

In Experiment 4, rats were returned to Context B and, after 2 min, received an unsignalled $0.4-, 0.8-$, or $1.0-\mathrm{mA}, 1$-sec footshock. This context training occurred on Day $4,1 \mathrm{~d}$ after the extinction retention test. The following day, rats were returned to the same context, and contextual freezing was measured for 5 min.

\section{Drug administration}

D-cycloserine (DCS; Sigma-Aldrich) was freshly dissolved in $0.9 \%$ (wt/vol) sterile saline. DCS was injected subcutaneously (in the nape of the neck) in a volume of $1.0 \mathrm{~mL} / \mathrm{kg}$ at a dose of $15 \mathrm{mg} /$ $\mathrm{kg}$. Control animals received saline injections at a volume of $1.0 \mathrm{~mL} / \mathrm{kg}$. The dose and time of injection were chosen based on previous findings (Ledgerwood et al. 2003). Rats were injected with saline or DCS 15 min prior to CS pre-exposure (Experiments 2 and 3 ) or CS extinction (Experiments 3 and 4; see Table 1). Rats were equated on DCS exposure by receiving a second injection $4 \mathrm{~h}$ after the start of pre-exposure or extinction; saline rats were administered DCS and DCS rats received saline in this second injection. Importantly, previous studies have demonstrated that DCS had no effect when injected $4 \mathrm{~h}$ after extinction training (Ledgerwood et al. 2003; McCallum et al. 2010).

\section{Scoring, exclusion criteria, and statistics}

Behavior was scored using a time-sampling procedure every $3 \mathrm{sec}$ as either freezing or not freezing, with the exception of the 10-sec conditioning trials which were scored every second. Freezing was defined as the absence of all movement except that required for breathing (Fanselow 1980). The total observations scored as freezing were summed and converted to a percentage. A second observer unaware of the experimental condition of each rat scored a $30 \%$ sample of test and retardation test data. The inter-rater reliability was very high $(r=0.96)$.

DCS does not facilitate extinction retention unless withinsession extinction learning occurs (Weber et al. 2007). Therefore, an extinction criterion was applied so that any rat with a $\leq 5 \%$ decrease in freezing from the first to the last extinction trial was excluded. Eight rats in Experiment 4 (two from the Saline$0.8 \mathrm{~mA}$ group, one from the DCS-0.8 $\mathrm{mA}$ group, three from the Saline-1.0 mA group, and two from the DCS-1.0 $\mathrm{mA}$ group) were 
excluded on this basis. No rats were excluded from Experiments 1-3. In Experiment 1, pre-CS data for extinction was not recorded for one rat and in Experiment 2, conditioning data for two rats (one each from Saline-0.4 mA and DCS-0.4 mA conditions) were not recorded due to a recording malfunction.

Analysis of pre-CS freezing using independent measures $t$-tests or ANOVA where appropriate did not detect any significant group differences in any experiment. Conditioning, extinction, test, and retardation test data were analyzed using ANOVA with orthogonal contrasts. Type I error rate $(\alpha)$ was controlled at 0.05 for each contrast tested.

\section{Acknowledgments}

This research was supported by the grant DP110100754 from the Australian Research Council to G.P.M. and R.R.

\section{References}

Baker JD, Azorlosa JL. 1996. The NMDA antagonist MK-801 blocks the extinction of Pavlovian fear conditioning. Behav Neurosci 110: 618-620.

Barak S, Weiner I. 2010. Dissociating scopolamine-induced disrupted and persistent latent inhibition: Stage-dependent effects of glycine and physostigmine. Psychopharmacology 209: 175-184.

Bertotto ME, Bustos SG, Molina VA, Martijena ID. 2006. Influence of ethanol withdrawal on fear memory: Effect of D-cycloserine. Neuroscience 142: 979-990.

Bouton ME. 2002. Context, ambiguity, and unlearning: Sources of relapse after behavioral extinction. Biol Psychiatry 52: 976-986.

Bouton ME, Bolles RC. 1979a. Contextual control of the extinction of conditioned fear. Learn Motiv 10: 445-466.

Bouton ME, Bolles RC. 1979b. Role of conditioned contextual stimuli in reinstatement of extinguished fear. J Exp Psychol Anim Behav Process 5: 368-378.

Bouton ME, Westbrook RF, Corcoran KA, Maren S. 2006. Contextual and temporal modulation of extinction: Behavioral and biological mechanisms. Biol Psychiatry 60: 352-360.

Bouton ME, Vurbic D, Woods AM. 2008. D-cycloserine facilitates context-specific fear extinction learning. Neurobiol Learn Mem 90: 504-510.

Chang C-H, Maren S. 2011. Medial prefrontal cortex activation facilitates re-extinction of fear in rats. Learn Mem 18: 221-225.

de Kleine RA, Hendriks G-J, Kusters WJC, Broekman TG, van Minnen A. 2012. A randomized placebo-controlled trial of D-cycloserine to enhance exposure therapy for posttraumatic stress disorder. Biol Psychiatry 71: 962-968.

Delamater AR. 2012. Issues in the extinction of specific stimulus-outcome associations in Pavlovian conditioning. Behav Processes 90: 9-19.

Falls W, Miserendino M, Davis M. 1992. Extinction of fear-potentiated startle: Blockade by infusion of an NMDA antagonist into the amygdala. J Neurosci 12: 854-863.

Fanselow M. 1980. Conditional and unconditional components of post-shock freezing. Pavlov J Biol Sci 15: 177-182.

Gaisler-Salomon I, Weiner I. 2003. Systemic administration of MK-801 produces an abnormally persistent latent inhibition which is reversed by clozapine but not haloperidol. Psychopharmacology 166: 333-342.

Gaisler-Salomon I, Diamant L, Rubin C, Weiner I. 2008. Abnormally persistent latent inhibition induced by MK801 is reversed by risperidone and by positive modulators of NMDA receptor function: Differential efficacy depending on the stage of the task at which they are administered. Psychopharmacology 196: 255-267.

Graham BM, Langton JM, Richardson R. 2011. Pharmacological enhancement of fear reduction: Preclinical models. Br J Pharmacol 164: $1230-1247$

Guastella AJ, Richardson R, Lovibond PF, Rapee RM, Gaston JE, Mitchell P, Dadds MR. 2008. A randomized controlled trial of D-cycloserine enhancement of exposure therapy for social anxiety disorder. Biol Psychiatry 63: 544-549.

Hofmann SG, Smits JAJ. 2008. Cognitive-behavioral therapy for adult anxiety disorders: A meta-analysis of randomized placebo-controlled trials. J Clin Psychiatry 69: 621-632.

Hofmann SG, Meuret AE, Smits JAJ, Simon NM, Pollack MH, Eisenmenger K, Shiekh M, Otto MW. 2006. Augmentation of exposure therapy with D-cycloserine for social anxiety disorder. Arch Gen Psychiatry 63: 298-304.

Holtzman O, Siette J, Holmes NM, Westbrook RF. 2010. Additional exposures reverse the latent inhibitory effects of recent and remote exposures. J Exp Psychol Anim Behav Process 36: 368-380.
Kaplan GB, Moore KA. 2011. The use of cognitive enhancers in animal models of fear extinction. Pharmacol Biochem Behav 99: $217-228$.

Kim JH, Li S, Richardson R. 2011. Immunohistochemical analyses of long-term extinction of conditioned fear in adolescent rats. Cereb Cortex 21: 530-538.

Kuriyama K, Honma M, Soshi T, Fujii T, Kim Y. 2011. Effect of D-cycloserine and valproic acid on the extinction of reinstated fear-conditioned responses and habituation of fear conditioning in healthy humans: A randomized controlled trial. Psychopharmacology 218: 589-597.

Kushner MG, Kim SW, Donahue C, Thuras P, Adson D, Kotlyar M, McCabe J, Peterson J, Foa EB. 2007. D-Cycloserine augmented exposure therapy for obsessive-compulsive disorder. Biol Psychiatry 62: $835-838$.

Lai CS, Franke TF, Gan WB. 2012. Opposite effects of fear conditioning and extinction on dendritic spine remodelling. Nature 483: 87-91.

Ledgerwood L, Richardson R, Cranney J. 2003. Effects of D-cycloserine on extinction of conditioned freezing. Behav Neurosci 117: 341-349.

Ledgerwood L, Richardson R, Cranney J. 2004. D-Cycloserine and the facilitation of extinction of conditioned fear: Consequences for reinstatement. Behav Neurosci 118: 505-513.

Ledgerwood L, Richardson R, Cranney J. 2005. D-cycloserine facilitates extinction of learned fear: Effects on reacquisition and generalized extinction. Biol Psychiatry 57: 841-847.

Lin C-H, Yeh S-H, Leu T-H, Chang W-C, Wang S-T, Gean P-W. 2003. Identification of calcineurin as a key signal in the extinction of fear memory. J Neurosci 23: 1574-1579.

Lubow RE. 1965. Latent inhibition: Effects of frequency of nonreinforced pre-exposure of the CS. J Comp Physiol Psychol 60: 454-457.

Lubow RE, Moore AU. 1959. Latent inhibition: The effect of nonreinforced pre-exposure to the conditional stimulus. J Comp Physiol Psychol 52: 415-419.

Mao S-C, Hsiao Y-H, Gean P-W. 2006. Extinction training in conjunction with a partial agonist of the glycine site on the NMDA receptor erases memory trace. J Neurosci 26: 8892-8899.

McCallum J, Kim JH, Richardson R. 2010. Impaired extinction retention in adolescent rats: Effects of D-cycloserine. Neuropsychopharmacology 35: 2134-2142.

Myers KM, Davis M. 2002. Behavioral and neural analysis of extinction. Neuron 36: $567-584$.

Myers KM, Carlezon WA Jr, Davis M. 2011. Glutamate receptors in extinction and extinction-based therapies for psychiatric illness. Neuropsychopharmacology 36: 274-293.

National Health and Medical Research Council (Australia). 2004. Australian code of practice for the care and use of animals for scientific purposes, 7th ed. National Health and Medical Research Council, Canberra, Australia.

Otto MW, Tolin DF, Simon NM, Pearlson GD, Basden S, Meunier SA, Hofmann SG, Eisenmenger K, Krystal JH, Pollack MH. 2010. Efficacy of D-cycloserine for enhancing response to cognitive-behavior therapy for panic disorder. Biol Psychiatry 67: 365-370.

Pearce JM, Hall G. 1980. A model for Pavlovian learning: Variations in the effectiveness of conditioned but not of unconditioned stimuli. Psychol Rev 87: 532-552.

Polack C, Laborda M, Miller R. 2012. Extinction context as a conditioned inhibitor. Learn Behav 40: 24-33.

Quirk GJ. 2002. Memory for extinction of conditioned fear is longlasting and persists following spontaneous recovery. Learn Mem 9: $402-407$.

Quirk GJ, Mueller D. 2008. Neural mechanisms of extinction learning and retrieval. Neuropsychopharmacology 33: 56-72.

Rescorla RA. 1969. Pavlovian conditioned inhibition. Psychol Bull 72: 77-94.

Rescorla RA. 1973. Effect of US habituation following conditioning. J Comp Physiol Psychol 82: 137-143.

Rescorla RA. 2004. Spontaneous recovery. Learn Mem 11: 501-509.

Rescorla RA, Heth CD. 1975. Reinstatement of fear to an extinguished conditioned stimulus. J Exp Psychol Anim Behav Process 1: 88-96.

Rescorla RA, Wagner AR. 1972. A theory of Pavlovian conditioning: Variations in the effectiveness of reinforcement and nonreinforcement. In Classical conditioning II: Current research and theory (ed. AH Black, WF Prokasy), pp. 64-99. Appleton Century Crofts, New York, NY.

Ressler KJ, Rothbaum BO, Tannenbaum L, Anderson P, Graap K, Zimand E, Hodges L, Davis M. 2004. Cognitive enhancers as adjuncts to psychotherapy: Use of D-cycloserine in phobic individuals to facilitate extinction of fear. Arch Gen Psychiatry 61: 1136-1144.

Richards RW, Sargent DM. 1983. The order of presentation of conditioned stimuli during extinction. Anim Learn Behav 11: 229-236.

Richardson R, Ledgerwood L, Cranney J. 2004. Facilitation of fear extinction by D-cycloserine: Theoretical and clinical implications. Learn Mem 11: 510-516. 
Robbins SJ. 1990. Mechanisms underlying spontaneous recovery in autoshaping. J Exp Psychol Anim Behav Process 16: 235-249.

Siegmund A, Golfels F, Finck C, Halisch A, Räth D, Plag J, Ströhle A. 2011. D-Cycloserine does not improve but might slightly speed up the outcome of in-vivo exposure therapy in patients with severe agoraphobia and panic disorder in a randomized double blind clinical trial. I Psychiatr Res 45: 1042-1047.

Sotres-Bayon F, Bush DEA, LeDoux JE. 2007. Acquisition of fear extinction requires activation of NR2B-containing NMDA receptors in the lateral amygdala. Neuropsychopharmacology 32: 1929-1940.

Sotres-Bayon F, Diaz-Mataix L, Bush DEA, LeDoux JE. 2009. Dissociable roles for the ventromedial prefrontal cortex and amygdala in fear extinction: NR2B contribution. Cereb Cortex 19: 474-482.

Storsve AB, McNally GP, Richardson R. 2010. US habituation, like CS extinction, produces a decrement in conditioned fear responding that is NMDA dependent and subject to renewal and reinstatement. Neurobiol Learn Mem 93: 463-471.

Storsve AB, McNally GP, Richardson R. 2012. Renewal and reinstatement of the conditioned but not the unconditioned response following habituation of the unconditioned stimulus. Behav Process 90: 58-65.
Vervliet B. 2008. Learning and memory in conditioned fear extinction: Effects of D-cycloserine. Acta Psychol 127: 601-613.

Vetere G, Restivo L, Novembre G, Aceti M, Lumaca M, Ammassari-Teule M. 2011. Extinction partially reverts structural changes associated with remote fear memory. Learn Mem 18: 554-557.

Walker DL, Ressler KJ, Lu K-T, Davis M. 2002. Facilitation of conditioned fear extinction by systemic administration or intra-amygdala infusions of D-cycloserine as assessed with fear-potentiated startle in rats. Neurosci 22: 2343-2351.

Weber M, Hart J, Richardson R. 2007. Effects of D-cycloserine on extinction of learned fear to an olfactory cue. Neurobiol Learn Mem 87: 476-482.

Westbrook RF, Jones ML, Bailey GK, Harris JA. 2000. Contextual control over conditioned responding in a latent inhibition paradigm. J Exp Psychol Anim Behav Process 26: 157-173.

Woods AM, Bouton ME. 2006. D-cycloserine facilitates extinction but does not eliminate renewal of the conditioned emotional response. Behav Neurosci 120: 1159-1162.

Received April 13, 2012; accepted in revised form June 7, 2012. 


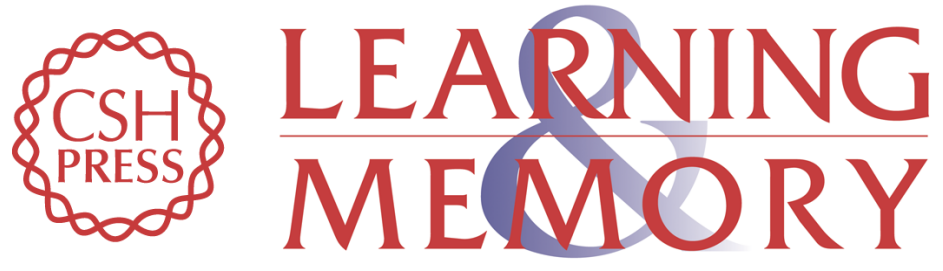

\section{d-cycloserine does not facilitate fear extinction by reducing conditioned stimulus processing or promoting conditioned inhibition to contextual cues}

Kathryn D. Baker, Gavan P. McNally and Rick Richardson

Learn. Mem. 2012, 19:

Access the most recent version at doi:10.1101/Im.026674.112

References This article cites 59 articles, 9 of which can be accessed free at: http://learnmem.cshlp.org/content/19/10/461.full.html\#ref-list-1

License

Email Alerting

Receive free email alerts when new articles cite this article - sign up in the box at the Service top right corner of the article or click here. 